\title{
Field Level Identification of Cinnamomum Species in Sri Lanka Using a Morphological Index
}

\author{
B.S. Bandusekara ${ }^{1,3}$, D.K.N.G. Pushpakumara ${ }^{2 *}$, P.C.G. Bandaranayake ${ }^{3}$, K.G.G. Wijesinghe ${ }^{4}$ and \\ G.G. Jayasinghe 4 \\ ${ }^{1}$ Postgraduate Institute of Agriculture, University of Peradeniya, Peradeniya, Sri Lanka \\ ${ }^{2}$ Department of Crop Science, Faculty of Agriculture, University of Peradeniya, Peradeniya, Sri Lanka \\ ${ }^{3}$ Agricultural Biotechnology Centre, Faculty of Agriculture, University of Peradeniya, Peradeniya, Sri Lanka \\ ${ }^{4}$ National Cinnamon Research and Training Centre, Palolpitiya, Thihagoda, Matara, Sri Lanka
}

\section{ARTICLE INFO}

\section{Article history:}

Received: 14 August 2019

Accepted: 07 November 2019

Revised version received: 12 September 2020

Available online: 1 October 2020

\section{Keywords:}

Cinnamomum

Ceylon Cinnamon

Leaf Morphological Index

Variation

Wild relatives

\section{Citation:}

Bandusekara, B.S., Pushpakumara,

D.K.N.G., Bandaranayake, P.C.G.,

Wijesinghe, K.G.G. and Jayasinghe, G.G.

(2020). Field Level Identification of

Cinnamomum Species in Sri Lanka Using a

Morphological Index. Tropical

Agricultural Research, 31(4): 43-53

DOI: http://doi.org/10.4038/tar.v31i4.8420

Bandusekara, B.S.

https://orcid.org/0000-0002-6382-1071

\section{ABSTRACT}

Cinnamomum zeylanicum Blume is a commercially important species cultivated in Sri Lanka and traded as Ceylon cinnamon or true cinnamon. In addition, seven endemic wild species of the genus Cinnamomum have been reported in Sri Lanka. The literature on wild relatives of $C$. dubium, C. capparucoronde, C. citriodorum, C. litseaefolium, C. ovalifolium, C. rivulorum and $C$. sinharajaense is limited. Therefore, proper field level identification and differentiation of both wild and cultivated species are critical for the conservation and utilization of such species. Since the cinnamon is a crosspollinated species, intra-species diversity is also a possibility. Our work focused on inter- and intra-species diversity of Cinnamomum leaf morphology to develop a "Leaf Morphological Index" for field-level identification of reported species. Forty accessions, representing a minimum of two from each species, collected from natural and cultivated habitats, were assessed with 12 morphological characters. The highest within-species variation was observed in $C$. zeylanicum, followed by $C$. dubium. Of the morphological characters, five-leaf traits, leaf shape, apex, base, venation, and size significantly contributed to the main principle components. Therefore, those traits were used for developing a leaf morphological index. The morphological index could distinguish all the species at the field level.

*Corresponding author : ngpkumara63@gmail.com 


\section{INTRODUCTION}

The genus Cinnamomum Schaeff, belongs to the family Lauraceae, and consists of about 250 species distributed in Asia, Australia, and the Pacific Islands. Of them, Cinnamomum zeylanicum Blume (syn. Cinnamomum verum J. Presl), C. cassia Blume and C. camphora Seib are commercially cultivated around the world. Other than C. zeylanicum, seven endemic wild species of the genus Cinnamomum have been reported in Sri Lanka (Kostermans, 1995). C. dubium Nees. is a widely distributed species whereas $C$. capparu-coronde Blume., C. citriodorum Thw., C. litseaefolium Thw., C. ovalifolium Wight., $C$. rivulorum Kosterm. and C. sinharajaense Kosterm. are found in limited habitats. $C$. ovalifolium and $C$. sinharajaense are only naturally grown in isolated habitats and do not exist in cultivation or other parts of the country (Kostermans, 1995). C. litseaefolium and $C$. rivulorum are categorized as endangered species in Sri Lanka while all other wild species are categorized as vulnerable species (MOE, 2012).

The demand for true cinnamon has an increasing trend worldwide as a high price spice crop due to ethnobotanical uses and recent scientific evidence on its medicinal and pharmacological properties. Several in vitro and in vivo evidences suggest that $C$. zeylanicum has anti-microbial, anti-parasitic, anti-oxidant and free radical scavenging properties and ability to lower blood glucose, serum cholesterol and blood pressure, suggesting beneficial cardiovascular effects (Shan et al., 2007; Singhe et al., 2007; Elumalai et al., 2011; Ranasinghe et al., 2013). Similarly, several other wild relatives of cinnamon have also gained worldwide attention recently.

The Cinnamomum flower has naturally evolved for cross-pollination, having "protogyneous-dichorgamy" breeding system, which may result in intraspecies genetic diversity (Krishnamoorthy et al., 1992). Therefore, field-level identification and differentiation of both wild and cultivated Cinnamomum species are challenging. Liyanage (2010) and Liyanage and Senanayake (2010) studied the distribution ecology of wild Cinnamomum in Sri Lanka. Abeysinghe and colleagues assessed the genetic relatedness of cultivated and wild cinnamon in Sri Lanka using cpDNA (Abeysinghe et al., 2009). Abeysignhe et al. (2014) also conducted a preliminary study on the identification of Cinnamomum species using randomly amplified polymorphic DNA (RAPD). Morphological differences among a few wild relatives and cultivated $C$. zeylanicum species were assessed (Ariyaratne et al., 2018). A study also suggested a possible correlation of leaf morphological traits with bark yield, oil yield, and oil quality (Wijesinghe et al., 2004). A key has been developed by Kostermans (1995) using the persistent nature of the perianth segment in the fruit cup, panicle length, leaf characters, and smell of various plant parts, although the use of this key is not pragmatic as panicle and flowers are not available throughout the year under field conditions. Kumarathilake (2012) developed a key for the identification of Sri Lankan Cinnamomum species based only on morphological characteristics including characteristics of immature bark. Recently, Azad and colleagues reported that some leaf morphological traits are age and environment independent (Azad et al., 2016). Consequently, the objective of the present study was to develop a morphological index and a practical botanical key for field-level identification of different Cinnamomum species present in Sri Lanka. The study was also extended to identify the within-species diversity of $C$. zeylanicum with special emphasis on recently released Sri Gemunu and Sri Wijaya varieties by the Department of Export Agriculture (DEA), Sri Lanka.

\section{MATERIALS AND METHODS}

\section{Sample collection}

Field surveys were carried out in seven agroecological regions to capture both within and between species diversity. A total of 40 samples including 30 wild and 10 cultivated plants were included in the analysis as given in Table 1. While some of the collections sites were new, others were selected based on the previous eco-geographic map developed by Liyanage (2010) and Liyanage et al. (2010). Cultivated C. zeylanicum samples were 
Table 1: Cinnamomum species used in the study and their sampling locations.

\begin{tabular}{|c|c|c|c|c|}
\hline \multirow[t]{2}{*}{ Species } & \multirow[t]{2}{*}{ Location } & \multirow[t]{2}{*}{ GPS coordinates } & \multicolumn{2}{|c|}{ Remarks } \\
\hline & & & Location & Origin \\
\hline \multirow{4}{*}{$\begin{array}{l}\text { C. capparu- } \\
\text { coronde }\end{array}$} & NCRTC, Thihagoda & E-6.0263 N-80.5616 & PL & $\mathrm{Cu}$. \\
\hline & NCRTC, Thihagoda & E-6.0258 N-80.5616 & PL & $\mathrm{Cu}$. \\
\hline & NCRTC, Thihagoda & E-6.0249 N-80.5616 & PL & $\mathrm{Cu}$. \\
\hline & MRS, Delpitiya & E-7.1346 N-80.5851 & PL & $\mathrm{Cu}$. \\
\hline \multirow[t]{3}{*}{ C. citriodorum } & NCRTC, Thihagoda & E-6.0225 N-80.5623 & PL & $\mathrm{Cu}$. \\
\hline & Balangoda-Norwood Road & E-6.7548 N-80.7204 & PL & NG \\
\hline & Watawala & E-6.5431 N-80.4344 & NL & NG \\
\hline$C$. & NCRTC, Thihagoda & E-6.0285 N-80.5610 & PL & $\mathrm{Cu}$. \\
\hline \multirow[t]{8}{*}{ Dubium } & NCRTC, Thihagoda & E-6.0279 N-80.5610 & PL & $\mathrm{Cu}$. \\
\hline & NCRTC, Thihagoda & E-6.0270 N-80.5610 & PL & $\mathrm{Cu}$. \\
\hline & MRS, Delpitiya & E-7.1334 N-80.5856 & PL & $\mathrm{Cu}$. \\
\hline & Sinharaja MAB & E-6.4108 N-80.5088 & NL & NG \\
\hline & Sinharaja MAB & E-6.4267 N-80.4146 & NL & NG \\
\hline & Balangoda-Norwood Road & E-6.7537 N-80.7200 & NL & NG \\
\hline & Balangoda-Norwood Road & E-6.7454 N-80.7440 & NL & NG \\
\hline & Balangoda-Norwood Road & E-6.7548 N-80.7224 & NL & NG \\
\hline \multirow[t]{3}{*}{ C. litseaefolium } & BGH, Hakgala & E-6.9683 N-80.7700 & PL & $\mathrm{Cu}$. \\
\hline & NCRTC, Thihagoda & E-6.0297 N-80.5600 & PL & $\mathrm{Cu}$. \\
\hline & MRS, Delpitiya & E-7.1325 N-80.5879 & PL & $\mathrm{Cu}$. \\
\hline \multirow{4}{*}{ C. ovalifolium } & HPNP, Ohiya & E-6.8035 N-80.8031 & NL & NG \\
\hline & HPNP, Ohiya & E-6.8025 N-80.8027 & NL & NG \\
\hline & HPNP, Ohiya & E-6.7948 N-80.8060 & NL & NG \\
\hline & BGH, Hakgala & E-6.9696 N-80.7700 & PL & $\mathrm{Cu}$. \\
\hline \multirow[t]{3}{*}{ C. rivulorum } & NCRTC, Thihagoda & E-6.0222 N-80.5624 & PL & $\mathrm{Cu}$. \\
\hline & NCRTC, Thihagoda & E-6.0228 N-80.5624 & PL & $\mathrm{Cu}$. \\
\hline & NCRTC, Thihagoda & E-6.0231 N-80.5624 & PL & $\mathrm{Cu}$. \\
\hline \multirow[t]{4}{*}{ C. sinharajaense } & NCRTC, Thihagoda & E-6.0241 N-80.5619 & PL & $\mathrm{Cu}$. \\
\hline & NCRTC, Thihagoda & E-6.0239 N-80.5619 & PL & $\mathrm{Cu}$. \\
\hline & NCRTC, Thihagoda & E-6.0235 N-80.5619 & PL & $\mathrm{Cu}$. \\
\hline & Sinharaja MAB & E-6.4352 N-80.4197 & NL & NG \\
\hline \multirow{4}{*}{$\begin{array}{l}\text { C. zeylanicum } \\
\text { (wild) }\end{array}$} & GONP, Bibila & E-7.1905 N-81.3745 & NL & NG \\
\hline & GONP, Bibila & E-7.1885 N-81.3732 & NL & NG \\
\hline & GONP, Bibila & E-7.1892 N-81.3711 & NL & NG \\
\hline & Balangoda-Norwood Road & E-6.7567 N-80.7315 & NL & NG \\
\hline \multirow{3}{*}{$\begin{array}{l}\text { C. zeylanicum (Sri } \\
\text { wijaya) }\end{array}$} & NCRTC, Thihagoda & & PL & $\mathrm{Cu}$. \\
\hline & MRS, Delpitiya & & PL & $\mathrm{Cu}$. \\
\hline & & & PL & $\mathrm{Cu}$. \\
\hline \multirow{3}{*}{$\begin{array}{l}\text { C. zeylanicum (Sri } \\
\text { gaтumu) }\end{array}$} & NCRTC, Thihagoda & & PL & $\mathrm{Cu}$. \\
\hline & MRS, Delpitiya & & PL & $\mathrm{Cu}$. \\
\hline & Nillambe & & PL & $\mathrm{Cu}$. \\
\hline
\end{tabular}

Note: $N L=$ New location, $P L=$ Previously known location, $C u=$ Cultivated plants, and $N G=$ Naturally grown plants.

collected from the following locations: The National Cinnamon Research and Training Centre (NCRTC), Palolpitiya, Thihagoda, Matara; Mid Country Research Station (MRS), Delpitiya; Sub Research Stations of Wariyagala, and Nillambe, and Hakgala
Botanical Gardens. Samples of naturally grown populations were collected from Sinharaja Man and Biosphere (MAB) Reserve, Gal Oya National Park (GONP), Bibila, Horton Plains National Park (HPNP) and BalangodaNorwood Road. Voucher specimens were 
prepared and identified using specimens at the National Herbarium at the Royal Botanical Gardens, Peradeniya, Sri Lanka.

\section{Selection of characters for the development of morphological index}

As the initial step, both wild and the cultivated species were evaluated on ten identified leaf morphological characters and two bark organoleptic characters. The leaf traits included leaf apex, base, shape, size, venation, margin, texture, arrangement, leaf colour and flush colour. The fragrance and taste of bark were included as bark traits. All the studied characters were recorded following the cinnamon descriptor (TURIS 2013 project, 2016). The $10^{\text {th }}$ leaf from the tip of the branch with no symptoms of pest and disease attack was selected for assessing leaf colour, texture, margin, and venation. The leaf and flush colour were recorded using the Royal Horticultural Society colour chart (RHS, 2015).

Principle component analysis (PCA) was performed on 12 characters to select the most appropriate traits for the total variance, and such characters were used to develop leaf morphological index. According to the PCA, the first PC (PC1) accounted for $63 \%$ of the total variance. Leaf venation pattern, leaf size, leaf base and leaf apex positively correlated with the PC1. The second PC (PC2) described $17 \%$ of the total variation and the leaf shape, colour, and bark fragrance contributed to the PC2 (Table 2). In order to develop the morphological index, age and environment independent leaf morphological characters such as shape, apex, and base (Azad et al., 2015), and venation pattern and leaf size were used.

Table 2: Total Variance explained based on the Principal Component Analysis.

\begin{tabular}{ccccc}
\hline \multirow{2}{*}{ Component } & \multicolumn{3}{c}{ Initial Eigen Values } \\
\cline { 2 - 5 } & Total & \% Variance & Cumulative \% \\
\hline 1 & 5.06 & 63 & 63 \\
2 & 1.39 & 17 & 80 \\
3 & 0.77 & 9 & 90 \\
4 & 0.61 & 9 & 100 \\
\hline
\end{tabular}

\section{Development of leaf morphological index}

Thirty matured leaves were selected from each plant and leaf shape, apex, base, and venation pattern along with size were observed. This was done for each species on four different characters (Table 3). Selected observations were grouped into four separate measurement scales by giving the lowest value to $C$. ovalifolium and the highest value to $C$. dubium. The values were assigned considering their morphological relativity previously described by Saumyasiri et al. (2006). Accordingly, C. ovalifolium and C. dubium are the most distinctly related (Saumyasiri et al., 2006) whilst other species are located in-between (Table 3). As such, four different morphological index-scoring scales were developed in this study for selected leaf characters (Table 3). The "Ideal Morphological Index Value" (IMIV) was introduced for each species by adding Morphological Index Score (MIS) values of the apex, base, shape and venation (Table 3). The leaf size was incorporated with the leaf shape (Figure 1 D). Both leaf apex and base were evaluated on a 1 to 10 score scale while leaf shape and the venation were evaluated on a 1 to 20 score scale (Table 3 and Figure 1). 
Table 3: Ideal morphological index values for genus Cinnamomum in Sri Lanka.

\begin{tabular}{|c|c|c|c|c|c|c|c|c|c|}
\hline \multirow{2}{*}{ Spp } & \multicolumn{4}{|c|}{ Typical observations } & \multicolumn{4}{|c|}{ Morphological Index Score (MIS) } & \multirow[t]{2}{*}{ IMIV } \\
\hline & Apex & Shape & Base & $\begin{array}{l}\text { Vena } \\
\text { tion }\end{array}$ & Apex & Shape & Base & $\begin{array}{c}\text { Venati } \\
\text { on }\end{array}$ & \\
\hline $\mathrm{C} 1$ & Obtuse & Oval & Acute & A & 1 & 3 & 1 & 2 & 7 \\
\hline$C 2$ & Acute & Ovate & Subacute & A & 3 & 3 & 3 & 2 & 11 \\
\hline C3 & Acuminate & $\begin{array}{l}\text { Narrowly } \\
\text { elliptic }\end{array}$ & Subacute & B & 5 & 3 & 3 & 5 & 16 \\
\hline$C 4$ & Acute & Lanceolate & Subscute & $\mathrm{C}$ & 3 & 8 & 3 & 7 & 21 \\
\hline C5 & Acute & Lanceolate & Obtuse & $\mathrm{C}$ & 3 & 8 & 8 & 7 & 26 \\
\hline C6 & Acute & Ovate & Rounded & $\mathrm{d} / \mathrm{c}$ & 3 & 12 & 10 & 9 & 34 \\
\hline$C 7$ & Acute & Oval & Obtuse & $\mathrm{d} / \mathrm{h}$ & 3 & 14 & 8 & 14 & 39 \\
\hline C8 & $\begin{array}{l}\text { Narrowly } \\
\text { acuminate }\end{array}$ & Elliptic & Obtuse & $\mathrm{e} / \mathrm{h}$ & 7 & 16 & 8 & 16 & 47 \\
\hline$C 9$ & $\begin{array}{c}\text { Short } \\
\text { acuminate }\end{array}$ & $\begin{array}{c}\text { Ovate- } \\
\text { lanceolate }\end{array}$ & Rounded & $\mathrm{F}$ & 6 & 20 & 10 & 18 & 54 \\
\hline C10 & $\begin{array}{c}\text { Long } \\
\text { acuminate }\end{array}$ & $\begin{array}{c}\text { Ovate- } \\
\text { lanceolate }\end{array}$ & Rounded & G & 10 & 20 & 10 & 20 & 60 \\
\hline
\end{tabular}

Note: $\mathrm{C} 1=C$. ovalifolium, $\mathrm{C} 2=C$. litseaefolium, $\mathrm{C} 3=C$. citriodorum, $\mathrm{C} 4=C$. capparu-coronde, $\mathrm{C} 5=C$. zeylanicum (wild), $\mathrm{C} 6=C$. zeylanicum (Sri Wijaya), C7=C. zeylanicum (Sri Gemunu), C8=C. sinharajaense, C9=C. rivulorum, C10=C. dubium. IMIV: Ideal morphological index values for different species

\section{Assessment of leaf morphological index values for genus Cinnamomum in Sri Lanka}

All the collected species were evaluated based on the developed morphological index (Figure 1) to address inter- and intra-species diversity. The MIS values were recorded for each species and the average morphological index score (AMIS) and standard deviations were calculated (Table 4). By adding all four AMIS together, an average morphological index value (AMIV) was introduced with standard deviations. Based on AMIV's standard deviations, morphological index value range (MIVR) was introduced for each species to address their morphological diversities (Table 4).

\section{Statistical analysis}

The technical replication depended on the availability of sampling locations. As such, $C$. ovalifolium, C. rivulorum, and C. citriodorum consisted of three replicates while $C$. capparucoronde, $C$. sinharajaense and C. litseaefolium had four replicates. Further, C. zeylanicum and $C$. dubium consisted of 9 replicates each. The principal component analysis (PCA) was performed including 12 observed characters to identify major components responsible for the total variation. Minitab (version 18) software package was used for statistical analysis.

\section{Development of botanical key for field level identification of Cinnamomum species}

A botanical key was developed for field-level identification of Cinnamomum species by modifying Kostermans (1995), Kumarathilake (2012), and Ariyarathne et al. (2018). Because of the limited availability of flowers and immature leaves throughout the year and difficulty in identifying the correct maturity stage, more attention was given to the leaf venation pattern and its association than to other characters. 


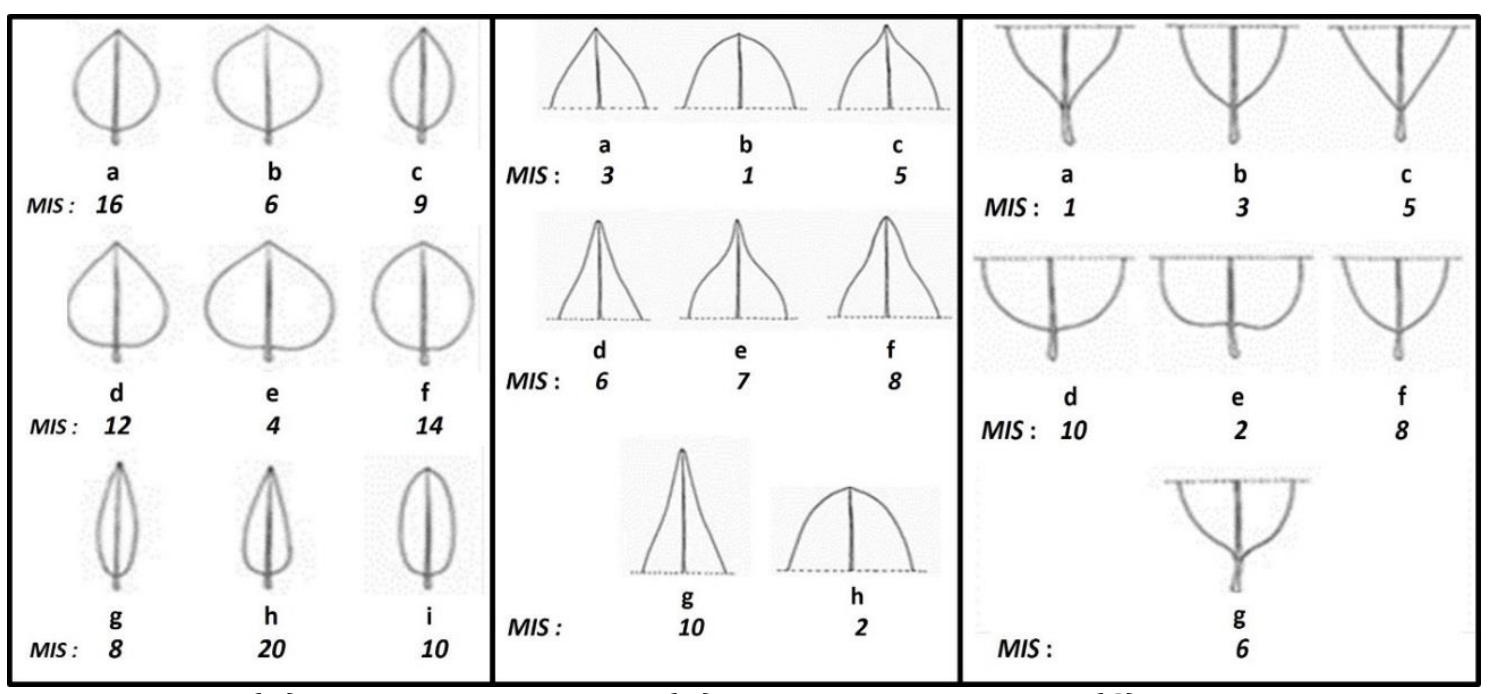

(A)

(B)

(C)

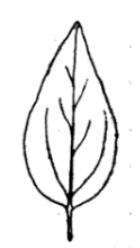

a

MIS: 2

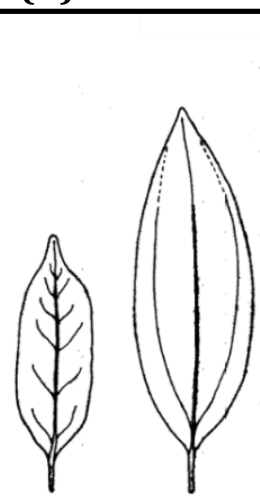

b c

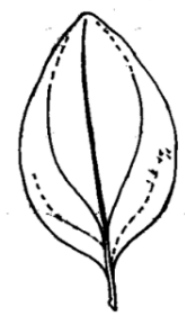

d

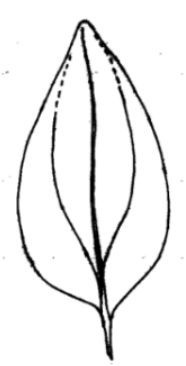

e

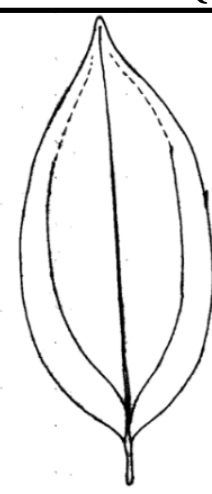

f
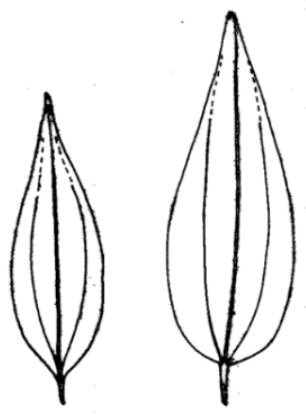

h

10

14

16

18

20

(D)

Figure 1: Leaf morphological characters and their index scores for genus Cinnamomum in Sri Lanka.

Notes: Leaf shape (A) (a- Elliptic, b- Broadly elliptic, c- narrowly elliptic, d-ovate, e- broadly ovate, f- oval, g- lanceolate, h- ovate-lanceolate, i- oblong-lanceolate); Leaf Apex (B) (a- Acute, b- Obtuse, c- Acuminate, d- Blunt, e- Long acuminate, f- Narrowly acuminate, g- Acuminate with broad acumen, h- Short acuminate); Leaf Base (C) (a- Acute, b- Subacute, c- Cuneate, d- Rounded, e- Subcordate, f- Obtuse, g Obtuse) and leaf venation (D) (a- C. ovalifolium, and C. litseaefolium, b- C. citriodorum, c- C. capparucoronde, d/e- C. zeylanicum, f- C. sinharajaense, g- C. rivulorum, h- C. dubium). MIS: Morphological index score; MIS leaf shape: for leaves with leaf length less than $10 \mathrm{~cm}, M I S$ should be divided by 4

\section{RESULTS AND DISCUSSION}

\section{Leaf morphological index}

Average morphological index values (AMIV) (Table 4) are useful in evaluating both inter and intraspecies morphological diversity. For example, mean separation values separated $C$. zeylanicum, C. sinharajaense, C. citriodorum and $C$. capparu-coronde each other, while $C$. ovalifolium, C. litseaefolium and C. rivulorum, C. dubium showed some overlapping. Nevertheless, the species could be differentiated in the field using morphological index value range (MIVR) together with specific morphological characters. Based on $A M I V$, the highest within-species variation was observed in $C$. zeylanicum followed by $C$. dubium. The lowest within species diversity was observed in C. citriodorum. 
Table 4: Calculated morphological index values for genus Cinnamomum in Sri Lanka.

\begin{tabular}{|c|c|c|c|c|c|c|}
\hline \multirow{2}{*}{ Species } & \multicolumn{4}{|c|}{$A M I S$} & \multirow{2}{*}{$A M I V$} & \multirow{2}{*}{$M I V R$} \\
\hline & Apex & Base & Shape & Venation & & \\
\hline C. ovalifolium & $1.7 \pm 0.9$ & $3.3 \pm 0.9$ & $2.1 \pm 0.6$ & $2.0 \pm 0.0$ & $9.1 \pm 2.1$ & $7-11$ \\
\hline C. litseaefolium & $2.3 \pm 1.2$ & $3.3 \pm 0.5$ & $4.7 \pm 2.9$ & $2.0 \pm 0.0$ & $12.3 \pm 3.5$ & $11-15$ \\
\hline C. citriodorum & $4.7 \pm 0.6$ & $3.7 \pm 1.2$ & $4.3 \pm 0.3$ & $5.0 \pm 0.0$ & $17.7 \pm 1.6$ & $16-19$ \\
\hline C. capparu-coronde & $3.5 \pm 0.4$ & $9.0 \pm 0.8$ & $3.8 \pm 1.6$ & $7.0 \pm 0.0$ & $23.3 \pm 2.2$ & $20-25$ \\
\hline C. zeylanicum (wild) & $3.7 \pm 0.5$ & $9.1 \pm 2.1$ & $8.7 \pm 0.2$ & $7.0 \pm 0.0$ & $28.4 \pm 2.5$ & $26-30$ \\
\hline C. zeylanicum (cult.) & $4.1 \pm 1.1$ & $13.2 \pm 2.8$ & $8.9 \pm 1.2$ & $9.1 \pm 2.5$ & $36.1 \pm 5.7$ & $31-41$ \\
\hline C. sinharajaense & $6.4 \pm 0.9$ & $15.8 \pm 1.7$ & $7.9 \pm 0.2$ & $15.9 \pm 0.9$ & $45.9 \pm 3.2$ & $42-48$ \\
\hline C. rivulorum & $7.9 \pm 0.9$ & $18.3 \pm 1.6$ & $8.9 \pm 0.6$ & $19.3 \pm 0.8$ & $54.4 \pm 2.6$ & $50-55$ \\
\hline C. dubium & $9.1 \pm 1.2$ & $18.4 \pm 3.1$ & $9.2 \pm 0.7$ & $19.8 \pm 0.3$ & $56.4 \pm 4.3$ & $55-60$ \\
\hline
\end{tabular}

$A M I V$ s are mean $\pm \mathrm{SD} ; A M I S=$ Average morphological index score; $A M I V=$ Average morphological index values for each species; $A M I V=A M S V$ (Apex) + AMSV (Base) + AMSV (Shape) + AMSV (Venation); $M I V R=$ Morphological index value range for species identification.

A closer relationship was reported among $C$. ovalifolium, C. litseaefolium and C. rivulorum, C. dubium (Saumyasiri et al., 2006; Saumyasiri et al., 2007). This study also provided closer $A M I V$ s in those species (Table 4) indicating AMIV also provides an idea about relationships among species. Interestingly, $C$. capparu-coronde and $C$. zeylanicum (wild) have close AMIVs, as such similar leaf shape, apex, and base (Figure $1(\mathrm{~A})(\mathrm{B})(\mathrm{C}))$. Nevertheless, these two species can be identified with unique volatiles and leaf types (Kostermans, 1995). While $C$. capparu-coronde leaf has a strong clove-like volatiles $C$. zeylanicum has unique cinnamon volatiles (Kostermans, 1995). Further, $C$. zeylanicum comprises of several leaf types; twisted, upward, or downward curled leaves while C. capparu-coronde, in general, has straight leaves.

The index developed in the current study could separate individuals of two varieties released by the DEA, Sri Lanka; variety Sri Gemunu has MIVs closer to 40 whilst variety Sri Wijaya has MIVs around 30. Hence, this index may also be useful in the identification of popular varieties among the other cultivated germplasm. For example, MIVs beyond 40 and less than 30 will not represent DEA recommended varieties.

Leaf morphological indexes have previously been developed and used in the identification of (i) both wild and cultivated species of japonica rice (Qian et al., 2000), (ii) natural variation, and the genetic control of the leaf expansion process of poplar (Hirokazu, 2002) and, (iii) the relationship between the morphological index and net photosynthesis by individual leaves of Quercus rubra seedlings (Hanson et al., 1986). Therefore, further studies on the association of morphological traits and yield parameters, biochemical properties, and other quality parameters are encouraged as such findings would be useful for the growers to assess the planting materials and the quality of harvest at the field level.

\section{Botanical key for field level identification of Cinnamomum Species}

The leaf venation pattern can also be used to differentiate species. In both $C$. rivulorum and $C$. dubium, two basal veins start at the leaf stalk junction together with the midrib and runs towards the apex (Figure 1 (D) g \& 
h). In other species, two basal veins start slightly above the base (Figure 1 (D)). Further, C. dubium can be separated from $C$. rivulorum, based on the arrangement of the basal veins where the basal veins of $C$. dubium run closer and parallel to the midrib especially at the mid-point (Figure 1 (D) h).

1. Venation: Prominent 3-veined structure

2. Venation: 2 basal veins visible less than half of the lamina length

3. Leaves: Broadly ovate shape......2. C. ovilifolium

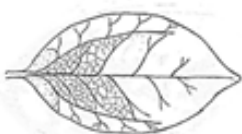

3. Leaves: Ovate to Ovate-lanceolate shape...3. C. litseaefolium

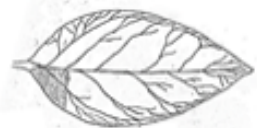

2. Venation: 2 basal veins visible more than half of the laminalength

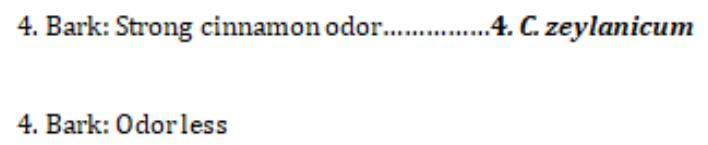

4. Bark: Strong cinnamon odor 4. C. zeylanicum

4. Bark: Odorless

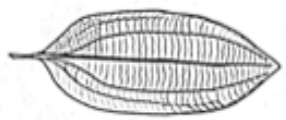

5. Venation, Leaves: 2 Basal veins running away from the midrib at the later part of the laminar, Clove like smell from leaf.

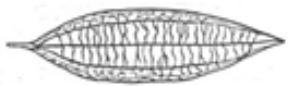

5. C. capparu-coronde

5. Venation, Leaves: 2 Basal veins running towards the midrib horizontally, Odorless leaf

6. Venation, Leaves: 2 Basal veins space horizontal to midrib, Eliptic shape

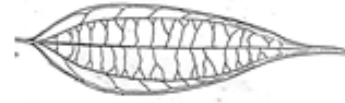

..6. C. sinharajaense

6. Venation, Leaves: 2 Basal veins closely horizontal to midrib,

Lanceolate to Ovate-lanceolate shape

7. Leaves: Chartaceous texture with Long-acuminate

apex.

7. C. dubium

7. Leaves:Subcoroceous texture with Short-acuminate apex.....................8. C. rivulorum

.1. C. citriodorum
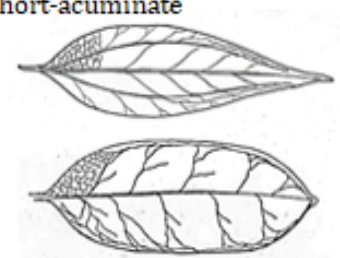

Figure 2: Revised key for identification of Cinnamomum species in the field level.

Besides, leaf texture and apex are also useful in the differentiation of $C$. rivulorum and $C$. dubium. For example, C. rivulorum has sub coriaceous texture and gradually acuminated apex while $C$. dubium has a chartaceous texture and long acuminated apex (Sritharan, 1984; Kostermans, 1995).
C. citriodorum consists of a clear pinnate venation pattern (Figure 1 (D) b) with strong citronella like fragrance, distinguishing it from the other species (Sritharan, 1984; Kostermans, 1995). Both C. litseaefolium and C. ovalifolium have a pinnate venation pattern with two short 
basal veins. Further, C. litseaefolium has twisted leaves with an upward curled leaf margin while $C$. ovalifolium has straight leaves with downward curled leaf margin. $C$. sinharajaense differs from others due to its large leaf size, elliptic leaf shape, and the prominent reticulated secondary venation pattern. As such, a botanical key was developed (Figure 2) including unique fieldlevel observations by modifying the key proposed by Kostermans (1995) giving major attention to the leaf venation.

This will be useful in the identification of species especially in the farmer's field and/or natural habitats without floral characters and chemical constituents as suggested by Kostermans (1995) and Ariyarathne et al. (2018). Further, the proposed key is developed without using characters of immature leaves (colour, thickness, and texture) as suggested by Kumarathilake (2012).

\section{CONCLUSIONS}

The leaf morphological index and the modified botanical key developed in this

\section{REFERENCES}

Abeysinghe, P.D., Samarajeewa, G.L. and Wijesinghe, K.G.G. (2014). Preliminary investigation for the identification of Sri Lankan Cinnamomum species using randomly amplified polymorphic DNA (RAPD) and sequence related amplified polymorphic (SRAP) markers. Journal of National Science Foundation Sri Lanka, 42, 201-208.

Abeysinghe, P.D., Gamaethige, K., Wijesinghe, G., Tachida, H. and Yoshda, T. (2009). Molecular characterization of cinnamon (Cinnamomum verum Presl) accessions and evaluation of genetic relatedness of cinnamon species in Sri Lanka based on trnL intron region, intragenic spacers between trnT-trnL, trnL-trnF, trnHpsbA and nuclear ITS. study are useful tools for accurate filed level identification of Cinnamomum species in Sri Lanka. Besides, the index can also be used to identify cultivated varieties such as $S r i$ Wijaya, Sri Gemunu from other species.

\section{ACKNOWLEDGEMENTS}

Authors wish to thank Prof. Siril Wijesundara and Dr. R.H.G. Ranil for the assistance given in the sample collection. Staff of the National Cinnamon Research and Training Centre, Palolpitiya, Matara, Mid Country Research Station DEA, Dalpitiya and the Agricultural Biotechnology Centre University of Peradeniya are acknowledged for their technical assistance provided. The Ministry of Primary Industries through the National Science Foundation of Sri Lanka provided the financial support (NSF/SP/CIN/2016/01) for the study.

Research Journal of Agriculture and Biological Sciences, 5(6), 1079-1088.

Ariyarathne, H.B.M.A., Weerasuriya S.N. and Senarath W.T.P.S.K. (2018). Comparison of morphological and chemical characteristics of two selected accessions and six wild species of genus cinnamomum schaeff. Sri Lankan Journal of Biology, 3(1), 11-23.

Azad, R., Senanayake, G., Wasantha Kumara, K.L., $\quad$ Ranawaka, R.A.A.K., Pushpakumara, D.K.N.G., Wijesinghe, K.G.G. and Geekiyanage, S. (2015) Morphological variation within progeny and deviations from mother plant reveal the allele richness in Cinnamomum verum germplasm: A case study from Deiyandara, Matara collection at the early vegetative 
stage. Tropical Agricultural Research and Extension 18 (4),163-167.

Azad, R., Ranawaka, R.A.A.K., Senanayake, G., Kumara, K.W., Wijesinghe, K.G.G., Pushpakumara, D.K.N.G. and Geekiyanage, S. (2016). Morphological variation of cinnamon (Cinnamomum verum Persl) germplasm in Matara District of Sri Lanka. International Journal of Minor Fruits, Medicinal and Aromatic Plants, 2(1), 6-14.

Elumalai, S., Keeavan, R., Ramganesh, S. and Murugasen, R. (2011). Isolation, purification and identification of the antidiabetic components from Cinnamomum zeylanicum and Cinnamomum cassia bark oil extracts. Current Botany, 2, 12-17.

Hanson, P.J., Dickson, R.E., Isebrands, J.G., Crow, T.R. and Dixon, R.K. (1986). A morphological index of Quercus seedling ontogeny for use in studies of physiology and growth. Tree Physiology, 2 (1-3), 273-281.

Hirokazu, T. (2002). The leaf index: heteroblasty, natural variation, and the genetic control of polar processes of leaf expansion. Journal of Plant \& Cell Physiology, 43, 372-378.

Kostermans, A.J.G.H. (1995). Lauraceae. pp. 112-129. In: M.D. Dassanayaka, F. Fosberg and W.D. Clayton (eds.) A revised handbook to the flora of Ceylon. Volume IX. Amerind Publishing Co. Pvt. Ltd., New Delhi, India.

Krishnamoorthy, B., Sasikumar, B., Rema, J., Gopalam, A. and Abraham, J. (1992). Variability and association studies in cinnamon (Cinnamomum verum). Journal of Spices and Aromatic Crops, 1, 148-150.

Kumarathilake, D.M.H.C. (2012) Study on the extinction risks, conservation and domestication of endemic wild Cinnamomum species in Sri Lanka. Unpublished M.Phil, Thesis, Faculty of
Agriculture, University of Ruhuna, Sri Lanka.

Liyanage, A.S.U. (2010). Eco-geographic survey of crop wild relatives. Plant Genetic Resource Centre, Gannoruwa, Peradeniya, Sri Lanka, pp. 133-164.

Liyanage, A.S.U. and Senanayake, G. (2010). The atlas of selected crop wild relatives in Sri Lanka. Colombo: Department of Agriculture, Sri Lanka, pp.11-73.

MOE (2012). The national red list 2012 of Sri Lanka; conservation status of the fauna and flora. Ministry of Environment, Colombo, Sri Lanka.

Qian, Q., He, P., Zheng, X., Chen, Y. and Zhu, L. (2000). Genetic analysis of morphological index and its related taxonomic traits for classification of indica/japonica rice. Science in China Series C: Life Sciences, 43, 113-119.

Ranasinghe, P., Pigera, S., Premakumara, G.A.S., Galappaththy, P. Constantine, G.R. and Katulanda, P. (2013) Medicinal properties of 'true' cinnamon (Cinnamomum zeylanicum): a systematic review. BMC Complementary and Alternative Medicine, 13, 275.

RHS. (2015). Royal Horticultural Society (RHS) Colour Chart (Edition 6). Royal Horticultural Society, London.

Saumyasiri, M.M.K.G., Yakandawala, D.M.D., Samaraweera, P. and Wijesinghe, K.G.G. (2006) Phylogenetic relationships of Cinnamomum species in Sri Lanka. Proceedings of the $11^{\text {th }}$ Peradeniya University Research Sessions, Volume 11. University of Peradeniya, Peradeniya. pp 134.

Saumyasiri, M.M.K.G., Yakandawala, D.M.D., Wijesinghe, K.G.G. and Samaraweera, P. (2007) Phenetic relationships of wild and cultivated accessions of cinnamon in Sri Lanka. Proceedings of the $11^{\text {th }}$ Peradeniya University Research Sessions - 2007: Volume 12 Part I - Agricultural, Biological and 
Medical Sciences. University of Peradeniya, Peradeniya. pp. 70-71.

Shan, B., Cai, Y., Brooks, J. D. and Corke, H. (2007). Antibacterial properties and major bioactive components of Cinnamon stick (Cinnamomum burmannii): activity against food borne pathogenic bacteria. Journal of Agricultural and Food Chemistry, 55, 5484-5490.

Singhe, G., Maurya, S., Lampasona, M.P. and Catalan, C.A.N. (2007). A comparison of chemical, antioxidant and antimicrobial studies of cinnamon leaf and bark volatile oils, oleoresins and their constituents. Science Direct, 45, 1650-1661.

Sritharan, R., (1984). The study of genus Cinnamomum. Unpublished M.Phil.
Thesis., Postgraduate Institute of Agriculture, University of Peradeniya, Sri Lanka

TURIS 2013 Project (2016). Descriptors for Cinnamon (Cinnamomum verum). University of Ruhuna, Matara.

Wijesinghe, K.G.G., Samaraweera, D.N., Jayasinghe, D. and Gunaratna, G.G. (2004). Development of Cinnamon (Cinnamomum verum Presl.) selection for higher yields with better quality characteristics. CARP Competitive Contract Research Grants Program. H.P.M. Gunasena, M.R. Dhanapala and T.U. Tilekawardana (Eds.), pp 3-10. Sri Lanka Council for Agricultural Research Policy, Wijerama Mawatha, Colombo 07. 